\title{
Alterações anatômicasinduzidas por Meloidogyne enterolobii (=M. mayaguensis) e Meloidogyne javanica em tomateiros resistentes a meloidoginose
}

\author{
Juliana Nogueira Westerich ${ }^{1}$, Roberto Antonio Rodella ${ }^{2}$, Juliana Magrinelli Osório Rosa ${ }^{1}$, Silvia Renata Siciliano Wilcken $^{1}$
}

UNESP - Universidade Estadual Paulista “Júlio de Mesquita Filho", Faculdade de Ciências Agronômicas, Departamento de Produção Vegetal, CP 237, 18603-970, Botucatu-SP. ${ }^{2}$ Departamento de Botânica, Instituto de Biociências de Botucatu - Universidade Estadual Paulista (IBB - UNESP), 18618-970, Botucatu (SP) Brasil

Autora para correspondência: Juliana Nogueira Westerich (julianawesterich@yahoo.com.br)

Data de chegada: 02/08/2011. Aceito para publicação em: 16/05/2012.

\section{RESUMO}

Westerich, J.N.; Rodella, R.A.; Rosa, J.M.O.; Wilcken, S.R.S. Alterações anatômicas induzidas por Meloidogyne enterolobii (=M. mayaguensis) e Meloidogyne javanica em tomateiros resistentes a meloidoginose. Summa Phytopathologica, v.38, n.3, p.192-197, 2012.

A resistência de tomateiros (Solanum lycopersicum L.) a $M$. incognita, M. javanica e $M$. arenaria, conferida pela presença do gene $M i$, não contempla a espécie $M$. enterolobii (=M. mayaguensis). $\mathrm{O}$ objetivo da pesquisa foi verificar as alterações anatômicas causadas por M. enterolobii no sistema radicular de porta-enxertos de tomateiro com o gene de resistência $M i$ ('Magnet' e Helper M') e compará-las com as causadas por $M$. javanica. As observações anatômicas das raízes foram feitas com auxílio de microscópio de luz e os aspectos mais relevantes foram fotografados. Com base em contagens e mensurações do tamanho dos sítios de alimentação e das células gigantes, foram efetuadas analises utilizando o método estatístico de
Análise de Agrupamento. O aparecimento de células nutridoras incitadas por $M$. enterolobii foi verificado em ambos os porta-enxertos de tomateiro, entre 10 e 17 dias após a inoculação (DAI). O número e a área de sítios de alimentação e de células gigantes foram menores aos 17 DAI do que aos 24 DAI. Nesta época (24 DAI), foram observados sítios de alimentação constituídos pela presença de várias células nutridoras multinucleadas, com parede celular espessa, citoplasma denso e granuloso. Os tecidos vasculares apresentaram-se comprimidos e desorganizados, foi observada, também, hipertrofia de células do parênquima cortical. As raízes inoculadas com $M$. javanica não apresentaram alterações anatômicas.

Palavras-chave adicionais: Células nutridoras, Histopatologia, Nematologia.

\section{ABSTRACT}

Westerich, J.N.; Rodella, R.A.; Rosa, J.M.O.; Wilcken, S.R.S. Anatomical Changes Induced by Meloidogyne enterolobii (=M. mayaguensis) and Meloidogyne javanica in Tomato Plants Resistant to the Root-Knot Nematode. Summa Phytopathologica, v.38, n.3, p.192-197, 2012.

The resistance of tomato plants (Solanum Lycopersicum L.) to $M$. incognita, M. javanica and M. arenaria, provided by the presence of $M i$ gene, does not include the species $M$. enterolobii (=M. mayaguensis). The aim of this study was to verify the anatomical changes caused by $M$. enterolobii in the root system of rootstocks from tomato plants with Mi resistance gene ('Magnet' and 'Helper M') and to compare these changes with those caused by $M$. javanica. The anatomical observations of roots were done with the aid of a light microscope and the most relevant aspects were photographed. Based on counts and measurements of the size of feeding sites and giant cells, the data were analyzed by using the statistical method of Cluster Analysis. The emergence of nurse cells stimulated by M. enterolobii was observed for both tomato rootstocks between 10 and 17 days after inoculation (DAI). The number and the area of feeding sites and giant cells were smaller at 17 DAI than at 24 DAI. On the latter occasion (24 DAI), there were feeding sites established by the presence of several multinucleate nurse cells with thick cell walls and dense and granular cytoplasm. Vascular tissues were compressed and disorganized; there was also hypertrophy of cortical parenchyma cells. Roots inoculated with $M$. javanica did not show anatomical changes.

Additional keywords: Nurse cells, Histopathology, Nematology.

O tomateiro (Solanum lycopersicum L.) tem os nematoides fitoparasitos como um de seus principais patógenos do sistema radicular, sendo o gênero Meloidogyne o mais importante, devido às complexas interações com seus hospedeiros.

Uma espécie que vem causando preocupação, devido à sua capacidade de multiplicação em plantas com resistência à meloidoginose, é M. enterolobii. Essa espécie foi descrita por Yang \& Eisenback (27) a partir de população encontrada em raízes de
Enterolobium contortisiliquum (Vell.) Morong, na ilha de Hainan, na China. De acordo com os mesmos autores, algodão, fumo 'NC 95', pimentão, melão e tomate são boas hospedeiras de $M$. enterolobii. Estudos conduzidos por Cantu et al. (2) demonstraram a suscetibilidade de diferentes porta-enxertos de tomateiro portadores do gene $M i$ a $M$. enterolobii.

No mecanismo de resistência ligado ao gene $M i$, os nematoides penetram as raízes e migram em direção ao cilindro vascular de maneira 
semelhante em plantas resistentes e suscetíveis. Entretanto, em plantas resistentes, não ocorre o desenvolvimento do sítio de alimentação. Ao invés disso, conforme Dropkin (9) e Ho et al. (12), desenvolve uma localizada região de células necróticas, também chamada de reação de hipersensibilidade (RH).

Portanto, assume grande importância a realização de estudos anatômicos radiculares, como os conduzidos em espinafre por Di Vito et al. (7), algodoeiro por Carneiro et al. (4), cafeeiro por Oliveira (18), soja por Moritz et al. (16) e melancia por Pontes et. al. (19), pois cultivares tidos como resistentes na presença de Meloidogyne spp. podem apresentar a formação de células gigantes e hipertrofia de células parenquimáticas, provocando a obliteração de parte dos elementos de vaso do xilema e a desorganização total do cilindro vascular, conforme citam Wanderley \& Santos (26).

Segundo Fonseca (10), estudos histopatológicos realizados em tecidos de plantas suscetíveis estão direcionados para origem e formação da célula gigante, além das alterações celulares e anatômicas causadas nas áreas adjacentes ao sítio de alimentação do nematoide. Corrêa \& Rodella (6) verificaram o desenvolvimento das células gigantes, estabelecendo as fases do ciclo de infestação de $M$. exigua em raízes de seringueira.

O estudo do processo de desenvolvimento de células gigantes induzidas por nematoides de galhas pode, portanto, auxiliar no entendimento da relação parasito-hospedeiro, bem como de suas alterações no sistema radicular e dos danos causados às culturas suscetíveis. Assim, o objetivo do trabalho foi verificar as alterações anatômicas causadas por $M$. enterolobii no sistema radicular de tomateiros com o gene $M i$ e compará-las com as alterações induzidas por M. javanica nas mesmas plantas.

\section{MATERIAL E MÉTODOS}

O estudo foi conduzido no Laboratório de Anatomia Vegetal, do Departamento de Botânica do Instituto de Biociências de Botucatu UNESP.

Sementes dos porta-enxertos de tomateiro 'Magnet' e 'Helper M', foram semeadas em bandejas de isopor com substrato esterilizado e, aos 14 dias após a germinação, foram transplantadas para o recipiente definitivo, em copos plásticos de $500 \mathrm{~m}^{3}$ contendo substrato de solo, areia e matéria orgânica $(1: 2: 1)$, previamente autoclavados.

A população de $M$. enterolobii utilizada foi obtida a partir de cultivo de pimentão 'Silver' de Campos Novos Paulista, SP, e a população de M. javanica foi obtida de raízes de pimentão 'Magali', proveniente do município de Santa Rosa, RS. Ambas foram identificadas pelo padrão perineal das fêmeas e pelo padrão eletroforético de isoenzimas conforme técnica descrita por Carneiro \& Almeida (3), no Laboratório da EMBRAPA - Recursos Genéticos e Biotecnologia, em Brasília.

As populações foram multiplicadas em raízes de tomateiro 'Rutgers' e mantidas em casa de vegetação (reguladas para não exceder $30^{\circ} \mathrm{C}$ ), localizada nas dependências do Setor de Defesa Fitossanitária do Departamento de Produção Vegetal da FCA-UNESP.

As suspensões de juvenis infectantes utilizadas como inóculo, foram obtidas de raízes de tomateiro 'Rutgers' altamente infectadas processadas de acordo com a técnica proposta por Hussey \& Baker (13) e modificada por Bonetti \& Ferraz (1). A suspensão resultante foi vertida em aparato de Baermann modificado de acordo com Southey (23) e colocada em estufa incubadora do tipo B.O.D., à temperatura de $30^{\circ} \mathrm{C}$, por três dias, para eclosão dos juvenis de segundo estádio
$\left(\mathrm{J}_{2}\right)$.

Após a primeira hora da instalação dos aparatos de Baermann modificados, a suspensão obtida foi recolhida e descartada para evitar a inclusão dos $\mathrm{J}_{2}$ eclodidos durante o processo de extração. Os $\mathrm{J}_{2}$ utilizados no experimento foram então recolhidos às 24,48 e 72 horas após a montagem das câmaras de eclosão e ao fim desse período, foi determinado o número médio de $\mathrm{J}_{2}$ na suspensão, com auxílio da Lâmina de Peters.

A infestação do solo presente nos copos plásticos foi feita com aproximadamente $500 \mathrm{~J} /$ volume padronizado de suspensão, ou seja, com $4 \mathrm{~mL}$, em quatro orifícios eqüidistantes com $3 \mathrm{~cm}$ de profundidade ao redor das plantas. Esta, foi efetuada uma semana após o transplantio dos porta-enxertos estudados. Posteriormente, essas plantas foram mantidas em B.O.D. a $26^{\circ} \mathrm{C}$.

O delineamento experimental utilizado foi inteiramente casualizado, constituído de quatro tratamentos [dois porta-enxertos de tomateiro, 'Magnet e Helper M', e duas espécies de nematoides das galhas, $M$. enterolobii e $M$. javanica], com cinco repetições. Cada parcela foi constituída por um copo plástico contendo uma única planta.

Foram realizadas quatro coletas após a inoculação das raízes com os nematoides, sendo feita a primeira coleta (época 1) aos 3 DAI (dias após a inoculação), a segunda (época 2) aos 10 DAI, a terceira (época 3) aos 17 DAI e a quarta (época 4) aos 24 DAI.

Para cada época de coleta, foram retiradas três plantas ao acaso, as quais tiveram as partes aéreas descartadas e os sistemas radiculares, após serem cuidadosamente lavados, secados em papel absorvente e pesados. A parcela a ser avaliada constituiu da metade do sistema radicular de cada planta.

Segmentos de 0,5-1,0 cm de comprimento das raízes infectadas foram amostrados nas regiões mediana e apical, e fixados em solução de FAA 50 (formol + ácido acético + álcool 50\%) por 48 horas e depois conservados em álcool $70 \%$ como proposto por Johansen (14). Posteriormente, esses segmentos foram submetidos à inclusão em historresina (resina metacrilato), de acordo com a técnica descrita por Gerrits (11).

Os segmentos foram dispostos em moldes plásticos (histomoldes) com solução de polimerização e mantidos em dissecador por 24 horas, para não absorver umidade; em seguida, foram colados em blocos de madeira com cola "Araldite", seccionados transversalmente em micrótomo rotatório Leica 2155 , com aproximadamente $8 \mu \mathrm{m}$ de espessura. Os cortes obtidos foram corados com floxine B por 15 minutos conforme técnica proposta por Taylor \& Sasser (25) e com azul de toluidina $0,05 \%$ em tampão acetato $\mathrm{pH} 4,7$ por 3 minutos como proposto por O'Brien et al. (17), sendo montados entre lâminas e lamínulas com resina sintética ("Permount").

As observações anatômicas das raízes foram feitas com auxílio de microscópio de luz e os aspectos mais relevantes foram fotografados em fotomicroscópio Olympus acoplado com câmera digital.

A análise quantitativa da anatomia radicular dos porta-enxertos 'Magnet' e 'Helper M' de tomateiro, inoculados com M. enterolobii $\mathrm{e}$ $M$. javanica, foi realizada apenas em três diferentes épocas de coleta, ou seja, aos 10 DAI (época 2), aos 17 DAI (época 3) e aos 24 DAI (época 4). Para se proceder à quantificação anatômica, os limites e contornos dos tecidos e das estruturas presentes na raiz foram desenhados com auxílio de microscópio de projeção e suas respectivas áreas foram mensuradas por meio de mesa digitalizadora apresentando programa computacional específico de acordo com Souza et al. (24). Foram determinadas as áreas da seção total da raiz, do conjunto epiderme e córtex, do cilindro vascular, do sitio de alimentação e da célula gigante, bem como foram efetuadas as contagens dos números 
de sítios de alimentação e de células gigantes.

Os dados obtidos, em três repetições, foram submetidos ao teste estatístico multivariado de Análise de Agrupamento segundo Sneath \& Sokal (22), procurando-se relacionar as estruturas anatômicas ocorrentes nos diferentes tratamentos, ou seja, porta-enxertos de tomateiro, espécies de nematoides e épocas de coleta, com a resistência a meloidoginose.

\section{RESULTADOS E DISCUSSÃO}

Não foram observadas alterações anatômicas nas raízes inoculadas com $M$. enterolobii aos 3 DAI. Alterações foram observadas apenas a partir de 10 DAI (época 2), evidenciando pequena desorganização no cilindro vascular de 'Magnet' e 'Helper M', devido ao parasitismo do nematoide (Figuras 1 e 2). Corrêa (5) observou a formação de galhas típicas em raízes de tomateiro somente 15 dias após a inoculação de M. incognita quando utilizados 5.000 juvenis.

Os sítios de alimentação de $M$. enterolobii foram observados a partir de 17 DAI (época 3), em ambos os porta-enxertos, cujas raízes apresentavam o cilindro vascular constituído por poucas células gigantes, multinucleadas, com 4 a 11 núcleos originários de sucessivas cariocineses, com citoplasma denso, bem como desorganização de células do córtex e do cilindro vascular (Figuras 3 e 4). Semelhantes resultados também foram relatados por Dropkin (9) e Corrêa (5) estudando plantas de tomateiro inoculadas com M. incognita.

A presença das células gigantes no cilindro vascular sugere um possível comprometimento de suas funções, através da alteração de sua quantidade e tamanho, acarretando em redução do transporte de água e nutrientes pelo xilema como verificado por Dorhout et al. (8).

Nas Figuras 5 e 6 observam-se os sítios de alimentação formados por M. enterolobii aos 24 DAI (época 4), em ambos os porta-enxertos de tomateiro. Nesta época, o córtex radicular apresentou-se com células indiferenciadas hipertrofiadas e hiperplásicas, sem células gigantes; enquanto o cilindro vascular encontrou-se desorganizado, deslocado do centro da estrutura, com células gigantes presentes, provocando a compressão e destruição do xilema, sendo este denominado por Krusberg \& Nielsen (15) e por Siddiqui \& Taylor (20) como xilema anormal.

As células gigantes do sítio de alimentação, aos 24 dias após a inoculação (época 4) apresentaram as paredes celulares espessas (Figuras 5 e 6). Foi observada também nessa época, a presença de

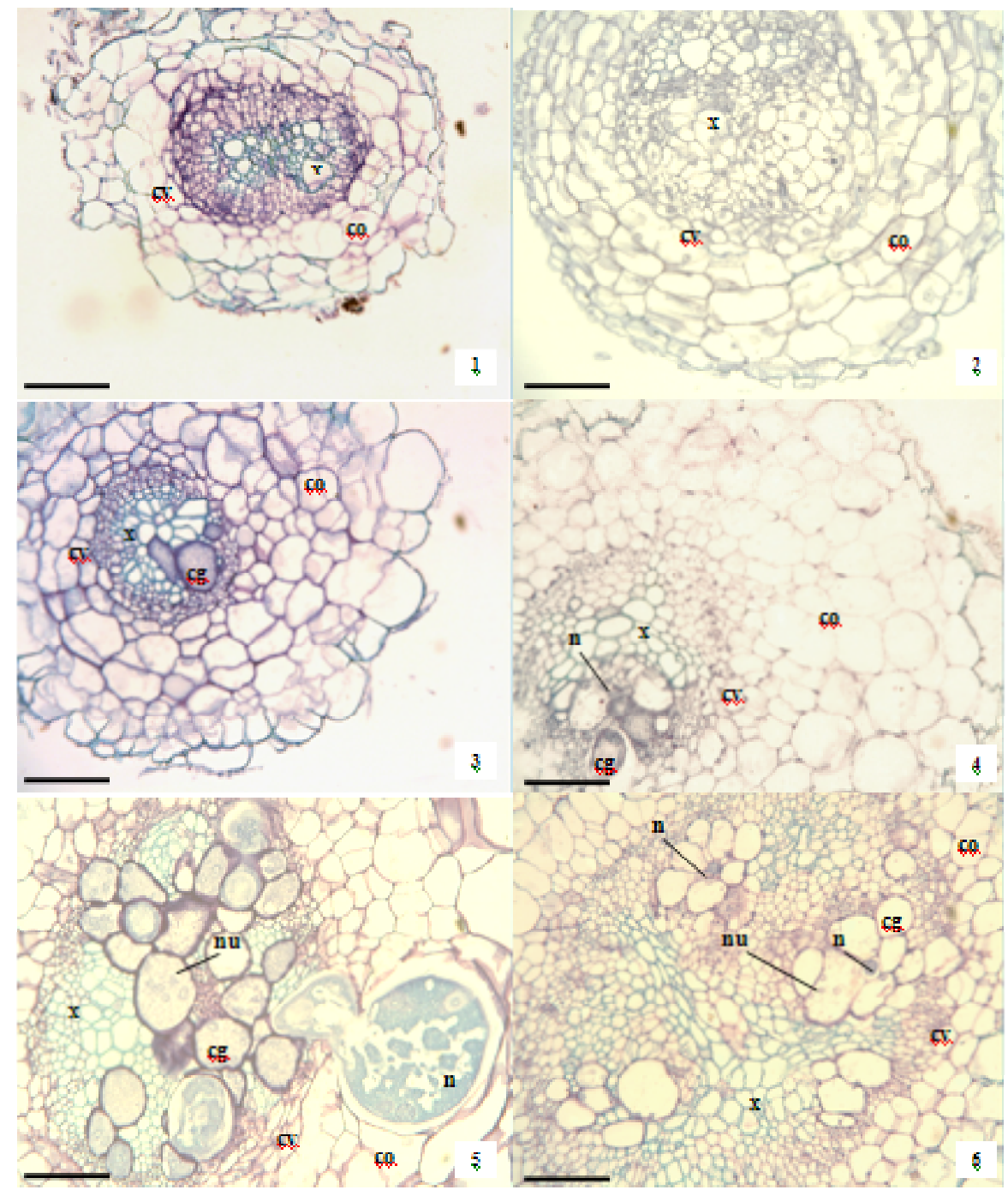

Figuras 1-6. Secções transversais de raízes dos porta-enxertos de tomateiro inoculadas com M. enterolobii. 1-3-5. 'Magnet'. 2-4-6. 'Helper M'. 1-2. Aos 10 dias após a inoculação. 3-4. Aos 17 dias após a inoculação. 5-6. Aos 24 dias após a inoculação. Células gigantes (cg), cilindro vascular (cv), córtex (co), nematoide (n), xilema (x), núcleo (nu). Barra $=25 \mu \mathrm{m}$. 
fêmeas em contato com o sítio de alimentação, caracterizando este sítio como eficiente para a nutrição do nematoide, uma vez que a ocorrência de cinco a nove células gigantes por sítio de alimentação é necessária para o desenvolvimento perfeito do nematoide, como afirmaram Silva et al. (21) para raízes de tomateiro parasitadas por $M$. javanica.

As raízes dos porta-enxertos 'Magnet' e 'Helper M' inoculadas com $M$. javanica não apresentaram alterações anatômicas nas três épocas avaliadas, como pode-se observar nas Figuras 7 e 8 , correspondente apenas à época 4 (24 DAI). Devido à presença de mecanismos de resistência nos porta-enxertos, conferidos pelo gene $M i$, o desenvolvimento de $M$. javanica foi comprometido, não sendo possível o estabelecimento do seu sítio de alimentação e, consequentemente, a espécie não completou o seu ciclo de desenvolvimento, como era esperado.

De acordo com Dropkin (9) e Ho et al. (12), em plantas resistentes, os nematoides penetram nas raízes e migram em direção ao cilindro vascular não ocorrendo o desenvolvimento do sítio de alimentação. Entretanto, desenvolveu-se ao redor da região anterior dos juvenis de segundo estádio $\left(\mathrm{J}_{2}\right)$ que penetraram uma região de células necróticas, também chamada de reação de hipersensibilidade $(\mathrm{RH})$.

A Tabela 1 mostra os valores médios de número e área dos sítios de alimentação e das células gigantes, bem como a área da seção total da raiz, do conjunto epiderme e córtex, e do cilindro vascular, avaliados em três épocas de coleta $(10,17$ e 24 DAI) das raízes dos portaenxertos 'Magnet' e 'Helper M' de tomateiro, após a inoculação com M. enterolobii e $M$. javanica, empregados para a realização da análise estatística multivariada.

Pode-se observar que o insucesso do parasitismo de $M$. javanica está demonstrado, como era esperado, pelo não desenvolvimento do seu sítio de alimentação nos porta-enxertos de tomateiro estudados (Tabela 1), enquanto que nos porta-enxertos inoculados com $M$. enterolobii, a área do sítio de alimentação é maior em 'Helper M' do que em 'Magnet', devido 'Helper M' apresentar um maior número de sítios de alimentação constituídos por maior número de células gigantes, entretanto o tamanho das células gigantes em 'Magnet' é maior do que em 'Helper M'.

O dendrograma resultante da Análise de Agrupamento (Figura 9) permitiu agrupar os tratamentos estudados, de forma que os pertencentes a um mesmo grupo apresentaram maior similaridade que os tratamentos de grupos diferentes. Os 12 tratamentos mostrados na Tabela 1 constituíram quatro grupos principais, ao nível de $0,16 \mathrm{da}$ escala de distância de similaridade, os quais apresentaram a seguinte disposição: Grupo 1 - formado por ambos os porta-enxertos de tomateiro 'Magnet' e 'Helper $\mathrm{M}$ ' inoculados com $M$. javanica nas três épocas de coleta $(10,17$ e $24 \mathrm{DAI})$ e também os dois portaenxertos ('Magnet' e 'Helper M') inoculados com M. enterolobii na segunda época de coleta (10 DAI), devido à espécie $M$. javanica não conseguir estabelecer o parasitismo e, a espécie $M$. enterolobii, não ter incitado o desenvolvimento do seu sítio de alimentação ainda; Grupo 2 - constituído pelos porta-enxertos 'Magnet' e 'Helper M' inoculados com M. enterolobii na terceira época (17 DAI), pois esta espécie de nematoide conseguiu, independente do porta-enxerto estudado, ter um desenvolvimento semelhante do sítio de alimentação; Entretanto, após $24 \mathrm{DAI}$, este desenvolvimento foi diferenciado ficando os portaenxertos separados em 2 grupos distintos, ou seja, Grupo 3 - formado apenas pelo porta-enxerto 'Magnet' inoculado com M. enterolobii na quarta época (24 DAI), apresentando menor número de sítios de alimentação e menor número de células gigantes; Grupo 4 - formado apenas pelo porta-enxerto de tomateiro 'Helper M' inoculado com $M$. enterolobii na quarta época (24 DAI), com maior número de sítios de alimentação e menor número de células gigantes.

Para M. javanica, os valores referentes aos sítios de alimentação e células gigantes foram nulos (Tabela 1), nas três épocas de coleta (10, 17 e 24 DAI), devido à resistência dos porta-enxertos a esse nematoide, portanto ficando estes tratamentos agrupados no grupo 1 juntamente com os tratamentos inoculados com M. enterolobii aos 10 DAI (época 2) (Figura 9).

M. enterolobii, aos 17 DAI (época 3), incitou menor número e menor área de células gigantes e de sítios de alimentação, em comparação com a época 4 (24 DAI). Os tratamentos M-Me-E3 e H-Me-E3, pertencentes ao grupo 2, não apresentaram dissimilaridade, ou seja, mostraram valores similares das características anatômicas analisadas (Figuras 3 e 4), constituindo-se, portanto, um agrupamento formado pelos dois porta-enxertos de tomateiro, 'Magnet' e 'Helper M', inoculados com M. enterolobii e avaliados aos 17 dias após a inoculação (época 3).

Aos 24 DAI (época 4), o número e a área dos sítios de alimentação e das células gigantes aumentaram em ambos porta-enxertos inoculados com M. enterolobii, ocorrendo dissimilaridade entre os porta-enxertos,
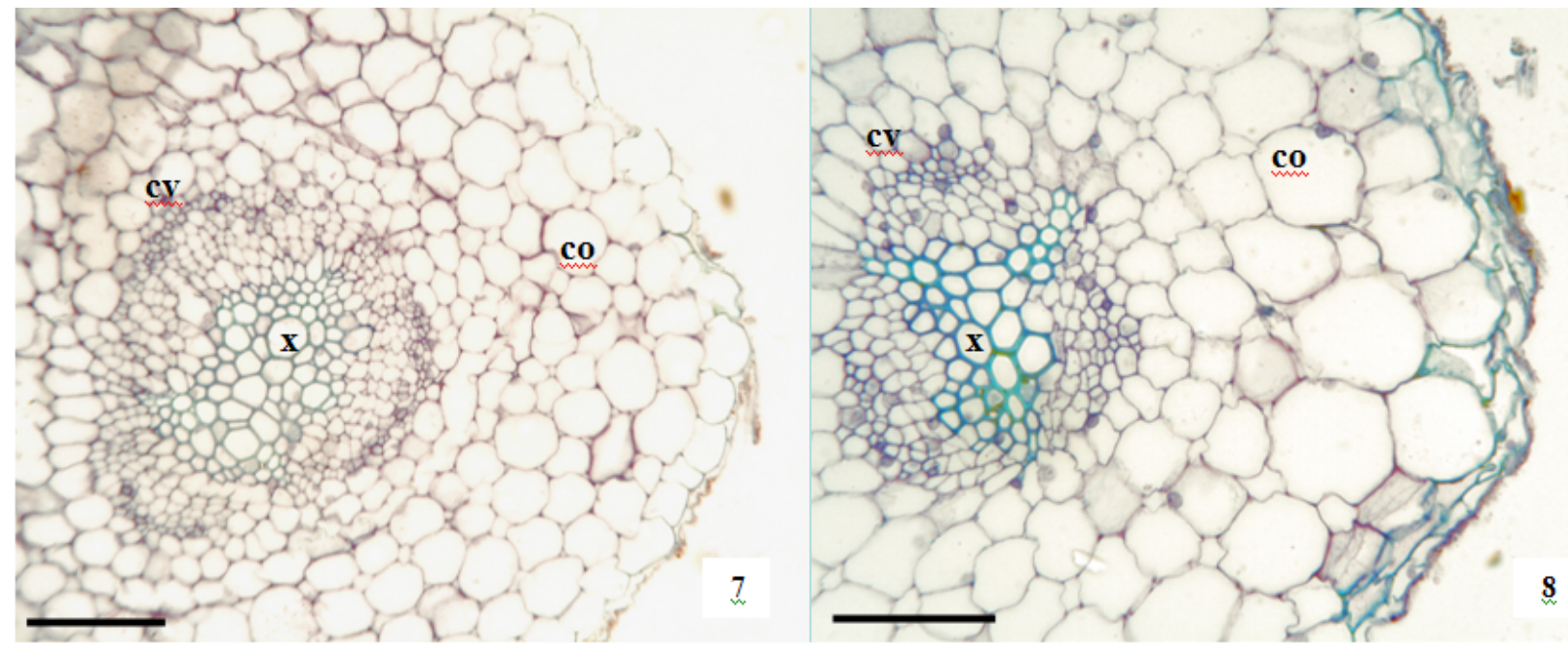

Figuras 7-8. Secções transversais de raízes dos porta-enxertos de tomateiro aos 24 dias após a inoculação com M. javanica. 7. 'Magnet'. 8. 'Helper M'. Cilindro vascular (cv), córtex (co), xilema (x). Barra $=25 \mu \mathrm{m}(7), 15 \mu \mathrm{m}(8)$. 
Tabela 1. Valores médios da área $\left(\mathrm{mm}^{2}\right)$ da seção total da raiz (ASR), do conjunto epiderme e córtex (AEpC), do cilindro vascular (ACV), da área $\left(\times 10^{-3} \mathrm{~mm}^{2}\right)$ do sítio de alimentação (ASA), da célula gigante (ACG), do número de sítios de alimentação (NSA) e do número de células gigantes (NCG), avaliados aos 10,17 e 24 dias após a inoculação (DAI) com M. enterolobii (Me) e M. javanica (Mj), em porta-enxertos de tomateiro 'Magnet' (M) e 'Helper M' (H).

\begin{tabular}{|c|c|c|c|c|c|c|c|c|}
\hline Tratamentos & Épocas & ASR & AEpC & $\mathrm{ACV}$ & ASA & ACG & NSA & NCG \\
\hline $\mathrm{M}-\mathrm{Me}$ & $17 \mathrm{DAI}$ & 0,60 & 0,48 & 0,12 & 8,11 & 1,50 & 1,67 & 5,33 \\
\hline $\mathrm{M}-\mathrm{Mj}$ & $10 \mathrm{DAI}$ & 0,22 & 0,20 & 0,02 & 0,00 & 0,00 & 0,00 & 0,00 \\
\hline $\mathrm{M}-\mathrm{Mj}$ & $17 \mathrm{DAI}$ & 0,20 & 0,16 & 0,04 & 0,00 & 0,00 & 0,00 & 0,00 \\
\hline $\mathrm{M}-\mathrm{Me}$ & $10 \mathrm{DAI}$ & 0,29 & 0,23 & 0,06 & 0,00 & 0,00 & 0,00 & 0,00 \\
\hline $\mathrm{M}-\mathrm{Me}$ & $17 \mathrm{DAI}$ & 0,98 & 0,87 & 0,11 & 7,01 & 1,07 & 1,33 & 6,67 \\
\hline $\mathrm{M}-\mathrm{Me}$ & 24 DAI & 1,92 & 1,52 & 0,40 & 103,00 & 1,71 & 7,67 & 51,67 \\
\hline $\mathrm{M}-\mathrm{Mj}$ & 10 DAI & 0,16 & 0,14 & 0,02 & 0,00 & 0,00 & 0,00 & 0,00 \\
\hline $\mathrm{M}-\mathrm{Mj}$ & 17 DAI & 0,21 & 0,17 & 0,04 & 0,00 & 0,00 & 0,00 & 0,00 \\
\hline
\end{tabular}

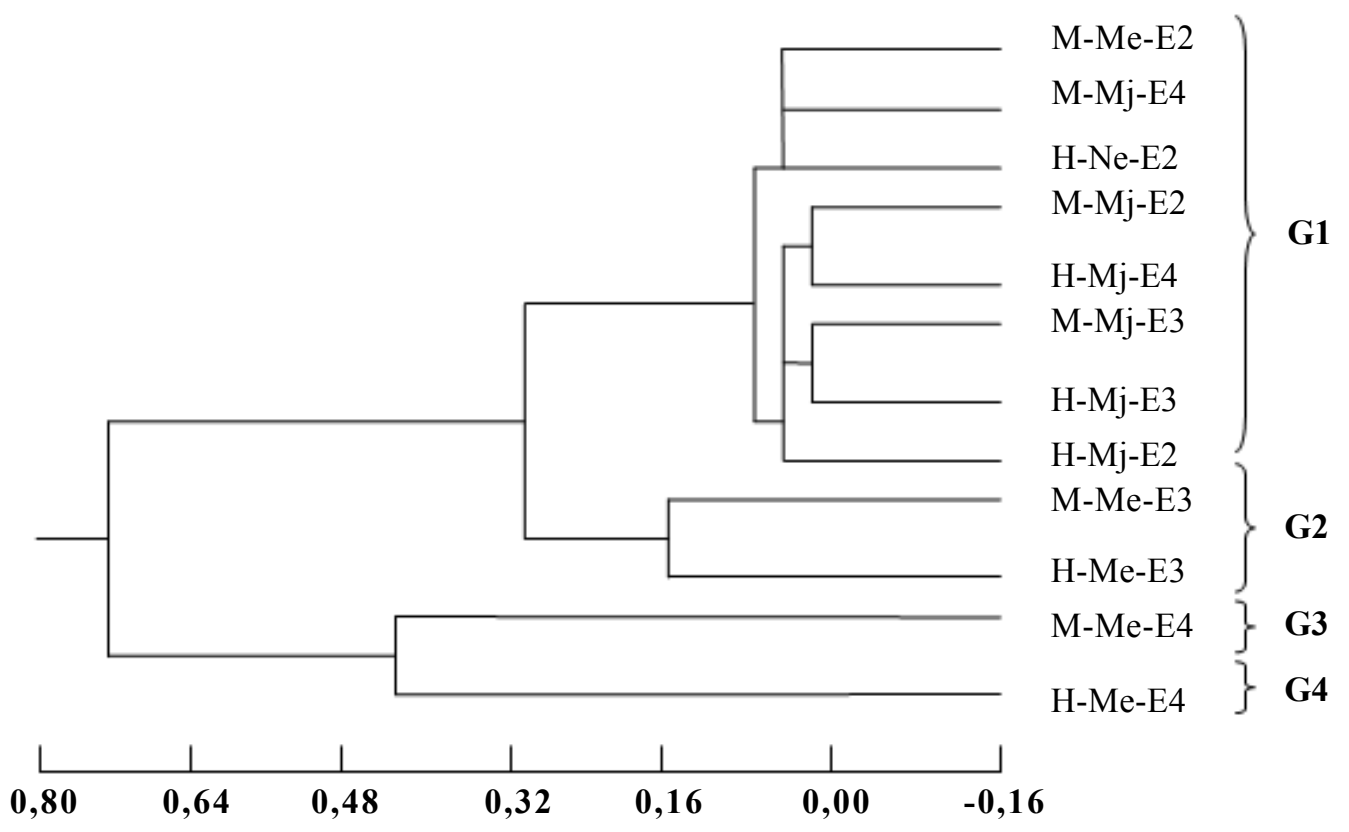

Figura 9. Dendrograma resultante da Análise de Agrupamento das sete características anatômicas quantitativas das raízes de porta-enxertos de tomateiro 'Magnet' e 'Helper M' inoculadas com M. enterolobii e M. javanica, utilizando-se a Distância Euclidiana Média entre os 12 tratamentos. M: Porta-enxerto de tomateiro 'Magnet'. H: Porta-enxerto de tomateiro 'Helper M'. Me: M. enterolobii. Mj: M. javanica. E2-E3-E4: Épocas referentes a 10, 17 e 24 dias após a inoculação. G1-G2-G3-G4: Grupos.

sendo que o 'Helper M' permitiu maior desenvolvimento dos sítios de alimentação e das células gigantes (Figuras 5 e 6 ).

Portanto, na relação $M$. enterolobii - raiz de tomateiro foi verificada no cilindro vascular, a formação de mais de um sítio de alimentação, constituídos pela presença de várias células nutridoras, caracterizadas pela ocorrência de parede celular espessa, citoplasma denso e granuloso, células multinucleadas e com vários vacúolos de pequeno tamanho. Os tecidos vasculares apresentaram-se comprimidos e desorganizados, observando-se também hipertrofia de células do parênquima cortical (Figuras 3-6).
Entretanto, a microscopia ótica não possibilitou a detecção dos fatores que interferem nas alterações anatômicas que permitem o sucesso do parasitismo de $M$. enterolobii nos porta-enxertos estudados, necessitando de outros estudos complementares.

\section{AGRADECIMENTOS}

Os autores agradecem à FAPESP pelo apoio financeiro concedido ao desenvolvimento do projeto de pesquisa (FAPESP 2008/58384-0) e, também, às empresas fornecedoras das sementes (Sakata Seed Sudamerica Ltda e Takii do Brasil Ltda.). 


\section{REFERÊNCIAS BIBLIOGRÁFICAS}

1. Bonetti, J.I.S.; Ferraz, S. Modificação do método de Hussey e Barker para extração de ovos de Meloidogyne exigua de raízes de cafeeiro. Fitopatologia Brasileira, Brasília, v.6, n.3, p.553, 1981.

2. Cantu, R.R.; Wilcken, S.R.S.; Rosa, J.M.O.; Goto, R. Reação de porta-enxertos de tomateiros a Meloidogyne mayaguensis. Summa Phytopathologica, Botucatu, v.35, p.124-126, 2009.

3. Carneiro, R.M.D.G.; Almeida, M.R.A. Técnica de eletroforese usada no estudo de enzimas dos nematoides de galhas para identificação de espécies. Nematologia Brasileira, Brasília, v.25, n.1, p.35-44, 2001.

4. Carneiro, R.M.D.G.; Neves, D.I. das; Falcão, R.; Paes, N.S.; Cia, E.; Grossi-de-Sá, M. de F. Resistência de genótipos de algodoeiro a Meloidogyne incognita raça 3 : reprodução e histopatologia. Nematologia Brasileira, Brasília, v.29, n.1, p.1-10, 2005.

5. Corrêa, C.F. Alterações anatômicas e fases do desenvolvimento de células gigantes induzidas por nematoides formadores de galhas (Meloidogyne spp.) em raízes de plantas suscetíveis. 2005. 150f. Tese (Doutorado em Ciências Biológicas/Botânica)-Universidade Estadual Paulista - Instituto de Biociências, Botucatu.

6. Corrêa, C.F.; Rodella, R.A. Caracterização das fases de desenvolvimento de células gigantes induzidas por Meloidogyne exigua em raiz de seringueira (Hevea brasiliensis Muell. Arg.). Nematropica, Florida, v.32, n.2, p.131-136, 2002.

7. Di Vito, M.; Vovlas, N.; Castillo, P. Host-parasite relationships of Meloidogyne incognita on spinach. Plant Pathology, Loughborough, v.53, p.508-514, 2004

8. Dorhout, R.; Gommers, F.J.; Kollöffel, C. Water transport through tomato roots infected with Meloidogyne incognita. Phytopathology, St. Paul, v.81, n.4, p.379-385, 1991.

9. Dropkin, V.H. The necrotic reaction of tomatoes and other hosts resistant to Meloidogyne: reversal by temperature. Phytopathology, Palo Alto, v.59, n.11, p.1632-1637, 1969.

10. Fonseca, H.S. Reações de porta-enxertos de seringueira (Hevea spp.) a Meloidogyne incognita (Kofoid and White, 1919) Chitwood, 1949 e histopatologia de raízes infectadas. 1996. 60f. Dissertação (Mestrado em Agronomia/Proteção de Plantas)-Universidade Estadual Paulista - Faculdade de Ciências Agronômicas, Botucatu.

11. Gerrits, P.O. The aplication of Glycol Methacrylate in histotecnology: some fundamental principles. Groningen: State University Groningen, 1991. 80p.

12. Ho, J.Y.; Weide, R.; Ma, H.M.; Wordragen, M.F.; Lambert, K.N.; Koornneef, M.; Zabel, P.; Williamson, V.M. The root-knot nematode resistance gene $(\mathrm{Mi})$ in tomato: construction of a molecular linkage map and identification of dominant cDNA markers in resistant genotypes. Plant Journal, London, v.2, p.971-982, 1992.
13. Hussey, R.S.; Baker, K.R. A comparison of methods of collecting inocula of Meloidogyne species, including a new technique. Plant Disease Report, Beltsville, v.57, p.1025-1028, 1973.

14. Johansen, D.A. Plant michrotechnique. New York: McGrawHill Book, 1940. 523p.

15. Krusberg, L.R.; Nielsen, L.W. Pathogenesis of root-knot nematodes to the Porto Rico variety of sweet potato. Phytopathology, St. Paul, v.48, p.30-39, 1958.

16. Moritz, M.P.; Carneiro, R.G.; Santiago, D.C.; Nakamura, K.C.; Pignoni, E.; Gomes, J.C. Histopatologia comparada das raízes de cultivares suscetível e resistente de soja inoculadas com Meloidogyne paranaensis. Nematologia Brasileira, Piracicaba, v.32, n.1, p.41-49, 2008.

17. O’Brien, T.P.; Feder, N.; McCully, M.E. Polychoromatic staining of plant cell walls by toluidine blue. O Protoplasma, Vienna, v. 59, n.2, p.368-373, 1964

18. Oliveira, D.S. Patogenicidade de populações de $M$. incognita, provenientes de Minas Gerais e São Paulo, ao cafeeiro. 2006. 75f. Tese (Doutorado em Agronomia/Fitopatologia)-Universidade Federal de Viçosa, Viçosa.

19. Pontes, M.F.C.; Pedrosa, E.M.R.; Guimarães, L.M.P.; Chaves, A. A nuclear dynamics of giant cells induced by Meloidogyne mayaguensis in watermelon roots. In: International Congress of Tropical Nematology, 2., 2009, Maceió. Anais... Maceió: Organization of Nematologists of Tropical America e Sociedade Brasileira de Nematologia, 2009. (1 CD-ROM).

20. Siddiqui, I.A.; Taylor, D.P. Histopathogenesis of galls induced by Meloidogyne naasi in wheat roots. Journal of Nematology, Jay, v.2, n.3, p.239-247, 1970.

21. Silva, G.S.; Ferraz, S.; Santos, J. M. Histopatologia de raízes de crotalária parasitadas por Meloidogyne javanica. Fitopatologia Brasileira, Brasília, v.15, n.1, p.46-48, 1990.

22. Sneath, P.H.A.; Sokal, R.R. Numerical taxonomy. San Francisco: 'W. H. Freeman, 1973. 573p.

23. Southey, J.F. Principles of sampling for nematodes: laboratory methods for work with plant and soil nematodes. London: Ministry of Agriculture, Fisheries and Food, 1986. 202p.

24. Souza, L.A.; Rosa; S.M.; Moscheta, I.S.; Mourão, K.S.; Rodella, R.A.; Rocha, D.C.; Lolis, M.I.G.A. Morfologia e anatomia vegetal: técnicas e práticas. Ponta Grossa: Universidade Estadual de Ponta Grossa, 2005. 194p.

25. Taylor, A.L.; Sasser, J.N. Biology, identification and control of root-knot nematodes (Meloidogyne sp.). Raleigh: North Carolina State University Graphics, 1978. 111p.

26. Wanderley, M.J.A.; Santos, J.M. Resistance of sweet potato cultivars to Meloidogyne incognita. Fitopatologia Brasileira, Brasília, v.29, n.4, p.437-440, 2004.

27. Yang, B.; Eisenback, J.D. Meloidogyne enterolobii n. sp. (Meloidogynidae), a root-knot nematode parasitising pacara earpod tree in China. Journal of Nematology, Hanover, v.15, p.381-391, 1983. 